\begin{tabular}{|l|l|} 
Jurnal Bimbingan dan Konseling Ar-Rahman \\
Volume 4, Nomor 2, Tahun 2018 \\
Tersedia Online: http://ojs.uniska.ac.id/index.php/BKA \\
e-ISSN 2477-6300
\end{tabular}

\title{
HUBUNGAN KECERDASAN INTERPERSONAL DENGAN OCB DAN SIKAP PADA PROFESI KEGURUAN GURU MTSN SE-KOTA BANJARMASIN
}

\author{
M. Yuliansyah ${ }^{12}$, I Nyoman Sujana Degeng ${ }^{2}$, Bambang Budi Wiyono ${ }^{2}$, dan Achmad Supriyanto ${ }^{2}$ \\ ${ }^{1}$ Universitas Islam Kalimantan Muhammad Arsyad Al-Banjari, Banjarmasin \\ ${ }^{2}$ Program Studi Manajemen Pendidikan, Pascasarjana, Universitas Negeri Malang \\ m-yuliansyahy@yahoo.com / 085102359191
}

\begin{abstract}
ABSTRAK
Penelitian ini dilakukan untuk mengetahui (1) Hubungan Kecerdasan Interpersonaldan Sikap Pada Profesi Keguruan dengan OCB Guru MTs Negeri Se-Kota Banjarmasin.Hasil penelitian menunjukan bahwa (1)tidak Terdapat hubungan tingkat Kecerdasan Interpersonal dengan Organizational Cittizenship Behaviour (OCB) Guru-Guru MTs Negeri Se-Kota Banjarmasin. (2) Terdapat hubungan tingkat Kecerdasan Interpersonal dan sikap Terhadap Profesi dengan OCB Guru-Guru MTs Negeri Se-Kota Banjarmasin.(3) Terdapat hubungan sikap Terhadap Profesi dengan OCB Guru-Guru MTs Negeri Se-Kota Banjarmasin. Direkomendasikan (1) Karena ada hubungan kecerdasan Interpersonal dengan OCB guru Di Madrasah Tsanawiyah Negeri se- Kota Banjarmasin, maka dalam memberdayakan guru-guru untuk melaksanakan proses belajar-mengajar di sekolah adalah untuk bertanggung jawab terhadap lingkungan kerjanya untuk mengatasi berbagai permasalahan yang dialami ketika melaksanakan tugassehingga ia bisa kreatif dinamis, (2) Penelitian menunjukan Sikap terhadap profesi yang baik menjadi salah satu dampak keberhasilan sekolah, karenanya sikap terhadap profesi seseorang guru yang erat kaitannya dengan kepribadian, perilaku, dan karakter guru. Oleh karenanya setiap guru harus memiliki kemampuan secara internal yang melakukan hubungan secara vertikal maupun horizontal, (3) penelitian ini diharapkan dapat menjadi bahan pengkajian peneliti selanjutnya sehingga dapat diperoleh perkembangan yang lainnya dari hubungan kecerdasan Interpersonalonal dan sikap terhadap profesi dengan OCB pada objek yang berbeda.
\end{abstract}

Kata Kunci: Kecerdasan Interpersonal; Sikap Pada Profesi Keguruan, Organizational Cittizenship Behaviour (OCB)

\section{ABSTRACT}

This study was conducted to determine (1) The relationship between emotional intelligence with intelligence and attitude Against Profession together with Cittizenship Organizational Behavior (OCB) Teachers MTs Negeri Banjarmasin. The population in this study is MTsNegeri as the city of Banjarmasin, amounting to 142 people. Samples determined through measures such as: set the proportional random sampling technique from each member of the sub-population based on the number of schools under study it was determined the sample of 105 people. The test for determining the validity and reliability are used to collect research data were then analyzed using linear regression and multiple regression.The results showed that (1) There is a level of emotional intelligence relationship with OCB Teachers MTs Negeri Banjarmasin. (2) There is a relationship and attitude level of Emotional Intelligence Professionals Against the OCB Teachers MTs Negeri se-Banjarmasin (3) There is a relationship Profession Against attitude with OCB Teachers MTs Negeri se-Banjarmasin.. Recommended (1) Since there is a relationship of emotional intelligence with teachers OCB MTs Negeri Banjarmasin, then in empowering teachers to implement the teaching-learning process in schools is to be responsible for the work environment for overcome the various problems faced when implementing the tasks so that he can be creative dynamic, (2) Research shows that a good attitude towards the profession into one of the effects of school success, hence the attitude towards one's profession is closely related to the teacher's personality, behavior, and character of the teacher. therefore every teacher should have the capability internally that having vertically or horizontally, (3) This study is expected to be the next research assessment materials that can be obtained more development of emotional intelligence relationship and attitude towards the profession with the OCB on an object that different.

Keywords: Emotional Intelligence Level Relationships; Attitudes Toward Profession; Work Discipline Teachers

Dipublikasikan Oleh :

UPT Publikasi dan Pengelolaan Jurnal

Universitas Islam Kalimantan Muhammad Arsyad Al-Banjari Banjarmasin 
M. Yuliansyah, I Nyoman Sujana Degeng, Bambang Budi Wiyono, dan Achmad Supriyanto

Jurnal Bimbingan dan Konseling Ar-Rahman

Volume 4, Nomor 2, Tahun 2018

e-ISSN 2477-6300

\section{PENDAHULUAN}

Berbeda dengan Sekolah Menengah Tingkat pertama (SMP) Madrasah Tsanawiyah sebagai lembaga pendidikan dasar yang siswanya tidak hanya menerima materi pelajaran yang sama dengan murid yang belajar di SMP dalam hal mata pelajara umum, tetapi di madrasah tsanawiyah sebagai lembaga pendidikan Islam menyajikan muatan materi keagamaan yang lebih besar di banding SMP, seperti : Qur'an-hadits, Aqidah-Akhlaq, Fiqih, Sejarah Kebudayaan Islam, dan Bahasa Arab. Sedangkan pada SMP rata-rata hanya mengalokasikan 2 jam pelajaran untuk mata pelajaran Pendidikan Agama Islam. Kenyataan ini menunjukkan bahwa madrasah tsanawiyah memiliki muatan kurikulum yang lebih banyak di banding SMP khususnya dalam hal Agama Islam. Perbedaan kurikulum ini tentunya menuntut adanya hubungan yang positif antara kecerdasan Interpersonal dan sikap pada profesi keguruan dengan organizational cittizenship behaviour (OCB) guru madrasah tsanawiyah negeri se-kota Banjarmasin.Kecerdasan Interpersonal merupakan suatu kapasitas yang mengidentifikasikan seberapa tinggi tingkat kompetensi personal dan sosial dari orang yang bersangkutan sehingga berkaitan erat dengan keadaan OCB dan sikap pada profesi keguruan.

\section{METODE}

Rancangan penelitian ini menggunakan pendekatan Kuantitatif, untuk menganalisis dan mendeskripsikan hubungan pengaruh kecerdasan Interpersonalonal (X1) terhadap Organizational Citizenship Behavior (OCB) (Y1) dan sikap profesi pada keguruan (Y2) guru madrasah Se Kota Banjarmasin dengan menggunakan analisis SEM (Structural Equation Modeling). Populasi Guru dari 4 MTsN yang ada di Kota Banjarmasin adalah 142 orang kemudian berdasarkan rumus distribusi proporsi didapatkan 105 sampel.

\section{Uji Validitas}

Uji validitas instrumen penelitian digunakan untuk memilih butir-butir pertanyaan yang relevan untuk dianalisis. Pengujian ini dilakukan dengan menggunakan teknik korelasi Produk Moment dari Karl Pearson. Bentuk rumus angka kasar yang digunakan untuk mencari koefisien dalam setiap variabel adalah sebagai berikut (Arikunto,2010: 171):

$$
r_{x y}=\frac{n \sum x_{1} y_{1}-\left(\sum x_{1}\right)\left(\sum y_{1}\right)}{\sqrt{\left[n \sum x_{i}^{2}-\left(\sum x_{1}\right)^{2}\right]\left[n \sum y_{1}-\left(\sum y_{1}\right)^{2}\right]}}
$$

\section{Uji Reliabilitas}

Uji reliabilitas dilakukan untuk mengetahui sesuatu instrumen cukup dapat dipercaya untuk dipergunakan sebagai alat pengumpul data, apabila instrumen tersebut sudah baik. Jadi uji reliabilitas instrumen dilakukan pada pertanyaan-pertanyaan yang valid. Pengujian reliabilitas instrumen penelitian menggunakan rumus Alpha Cronbach sebagai berikut (Sugiyono $2012: 365$ ).

Rumus koefisien reliabilitas Alfa Cronbach :

$r_{i}=\frac{k}{(k-1)}\left\{1-\frac{\sum S_{i}^{2}}{S_{t}^{2}}\right\}$

Berdasarkan tabel di atas hasil uji mengenai validitas dan reliabilitas itulah peneliti membuat keputusan tentang mutu instrumen penelitiannya. Kriteria tinggi rendahnya validitas atau reliabilitas instrumen, bila dinyatakan rendah maka menyusun ulang/memperbaiki instrumennya dan kriteria tinggi maka koesioner subjek penelitian tersebut dapat digunakan untuk mengumpulkan data penelitiannya (Suryabrata, 2003:60-63).

Teknik analisis data dalam penelitian ini adalah menggunakan :

\section{Uji Konstruk}

Analisis data menggunakan structural equation modeling (SEM), diperlukan asumsi-asumsi yang harus dipenuhi. Asumsi-asumsi ini harus diuji terlebih dahulu agar penggunaan SEM dapat diteruskan. Uji asumsi inimeliputi jumlah sampel, normalitas data, dan outlier. Untuk uji asumsi ini dapat dipergunakan software SPSS 24.0 dan dapat juga digunakan AMOS.

\section{Analisis Data dengan SEM}

Pengujian model hubungan antar variabel, yang berkaitan dengan analisis jalur (path analysis) dan model struktural, digunakan pemodelan persamaan structural atau structural equation modeling (SEM). Melalui SEM, dapat dilakukan 3 kegiatan secara bersamaan, yaitu pengecekan validitas dan reliabilitas instrument, pengujian model hubungan antar variabel, dan model untuk prediksi (terkait dengan analisis regresi).

\section{HASIL DAN PEMBAHASAN \\ Uji Validitas Instrumen}

Uji validitas Instrumen dilakukan untuk mengetahui tingkat kuvali dan atau derajat ketepatan dari instrument yang digunakan dalam pengumpulan data.

Suatu instrumen diusahakan valid apabila mampu mengukur apa yang diinginkan dan dapat mengungkap data dari variabel yang diteliti dengan tepat. Tinggi rendahnya validitas menunjukkan sejauh mana data yang terkumpul tidak menyimpang dari gambaran tentang variabel yang dimaksud, untuk mengetahui Valid atau tidaknya suatu item/ indikator instrumen, maka terlebih dahulu dilakukan percobaan dengan membandingkan indeks korelasi Pearson Product 
Moment dengan level signifikansi dengan degre of convidence $95 \%$ pada 105 responden, dengan nilai kritisnya $\mathrm{r}_{\text {tabel }}$ pada tingkat signifikansi $\square=5 \%$ dengan derajat bebas $=\mathrm{n}-(\mathrm{k}+1)=105-(5+1)=99$ adalah sebesar 0,164 .

Hasil uji Korelasi Product Moment pada Variabel OCB Guru (Y1) berkorelasi secara signifikan dengan tabel skor yang ditunjukkan nilai indeks korelasi Pearson Product Moment dengan level signifikansi dengan degre of convidence $95 \%$ lebih besar dari pada $\mathrm{r}_{\text {tabel }}$ tingkat signifikansi $\square=5 \%$ sehingga instrument terhadap semua indikator yang membentuk variabel Variabel OCB Guru (Y1) dinyatakan valid dan dapat digunakan untuk menguji hipotesis.

Hasil uji Korelasi Product Moment pada Variabel Sikap terhadap Profesi Guru (Y2) berkorelasi secara signifikan dengan tabel skor yang ditunjukkan nilai indeks korelasi Pearson Product Moment dengan level signifikansi dengan degree of convidence $95 \%$ lebih besar dari pada $\mathrm{r}_{\text {tabel }}$ tingkat signifikansi $\square=5 \%$ sehingga instrument terhadap semua indikator yang membentuk Variabel Sikap terhadap Profesi Guru (Y2)dinyatakan valid dan dapat digunakan untuk menguji hipotesis.

\section{Uji Reliabilitas Instrumen}

Uji Reliabilitas digunakan untuk menguji konsistensi alat ukur yang digunakan. Kuesioner sebagai alat ukur dinyatakan konsisten apabila mengukur sesuatu secara berulang kali memberikan hasil yang sama atau konsisten. Suatu indikator dikatakan reliabel jika nilai alpha Cronbach $>0,6$. Hasil uji reliabilitas Instrument dapat dilihat sebagai berikut.

Tabel 1. Hasil Uji Reliabilitas

\begin{tabular}{lll}
\hline Variabel & Reliabilitas & Keterangan \\
\hline Kecerdasan Interpersonal $\left(\mathrm{X}_{1}\right)$ & 0,863 & Reliabel \\
OCB Guru (Y1) & 0,936 & Reliabel \\
Sikap terhadap Profesi Guru (Y2) & 0,928 & Reliabel \\
\hline
\end{tabular}

Dari hasil pengujian reliabilitas seperti tertera pada tabel 5.17 dapat dinyatakan bahwa semua variabel yang diteliti dinyatakan reliable karena nilainya lebih besar dari 0,6 . Kesimpulan yang dapat diambil bahwa nilai reliabilitasnya dikategorikan sangat tinggi karena berada pada kisaran di atas 0,80 .

\section{Uji Hasil Analisis SEM}

Bagian ini menyajikan hasil analisis awal sebelum pengujian full model persamaan struktural (SEM). Variabel laten dalam model penelitian akan diperiksa dengan pembahasan tingkat keandalan dalam membangun variabel melalui model Confirmatory Factor Analysis (CFA).

\section{Evaluasi Terhadap Normalitas}

Uji normalitas dilakukan untuk mengetahui apakah data berdistribusi normal atau tidak pada setiap indikatornya (univariate) maupun multivariate. Jika digunakan tingkat signifikansi 5\%, maka Data dinyatakan normal secara univariate maupun multivariate apabila nilai Critical Ratio (CR) pada Skewness diharapkan berada di antara $-2,58<\mathrm{CR}<$ 2,58. Hasil selengkapnya dapat dilihat pada Tabel 2.

Berdasarkan Tabel 5.5 dapat dijelaskan sebagai berikut : Nilai critical ratio skewness berada di antara $-2,58<\mathrm{CR}<2,58$ dan pada nilai CR Skewness terkecil pada variabel X12, X13 dan Y11 lebih rendah dari rentang CR Skewnes dan pada nilai CR Skewness tertinggi pada variabel X12 dan X13 berada diatas rentang CR Skewness sehingga dapat diasumsikan bahwa tidak semua data terdistribusi secara normalsedangkan padanilai Multivariate normal bernilai 15,814 sehingga distribusi multivariate normal dan telah memenuhi syarat.

\section{Evaluasi Terhadap Outliers}

Pemeriksaan adanya outlier univariate dapat dilakukan dengan menentukan nilai ambang batas yang dikategorikan sebagai outlier dengan cara mengkonversikan nilai data penelitian ke dalam skor standar atau yang biasa disebut $z$-score. Untuk sampel besar (diatas 80 observasi), evaluasi terhadap outlier secara univariate terjadi jika nilai $z$-score di luar rentang -4 sampai dengan 4 (Hair et al., 1995:59).

Evaluasi outlier Mahalanobis Distance dapat dilakukan dengan menentukan ambang batas yang dikategorikan sebagai outlier dengan cara dengan membandingkan Nilai Mahalanobis hitung < Chi Square Distribution Table. Untuk nilai Chi Square Distribution Table dengan derajat bebas sebanyak 24(Jumlah indikator Variabel) pada tingkat signifikansi $0,05 \quad(* * *)$ maka nilai Mahalanobis sebesar 36,415. Berdasarkan Tabel 5.20 dapat dijelaskan sebagai berikut : Nilai Mahalanobis hitung pada seluruh seluruh Number Observation berada pada jarak minimal sebesar 31,468 dan maksimal sebesar 62,166 serta nilai $\mathrm{p} 1<0,05$. maka dapat dinyatakan bahwa sebaran data seluruh Number Observation tersebut tidak ada outlier. meskipun

Dipublikasikan Oleh :

UPT Publikasi dan Pengelolaan Jurnal

Universitas Islam Kalimantan Muhammad Arsyad Al-Banjari Banjarmasin 
M. Yuliansyah, I Nyoman Sujana Degeng, Bambang Budi Wiyono, dan Achmad Supriyanto Jurnal Bimbingan dan Konseling Ar-Rahman

Volume 4, Nomor 2, Tahun 2018

e-ISSN 2477-6300

dalam hal ini ada responden menunjukkan adanya gejala outliers multivariate, dalam analisis ini gejala outlier multivariate tampak responden nomor 19, 21 dan 55 akan tetapi observasi ini tidak dihilangkan dari analisis selanjutnya, karena tidak terdapat alasan khusus pada profil responden (Ferdinand, 2000: 226). Untuk itu, beberapa observasi yang bersifat outlier multivariate tetap dianalisis.

\section{Confirmatory Factor Analysis (CFA)}

Uji Confirmatory Factor Analysis (CFA) dan Uji Convergent Validitas dilakukan bertujuan untuk mengkonfirmasi setiap indikator yang sudah dibuat berdasarkan penelitian terdahulu maupun teori yang sudah ada dapat digunakan untuk menjelaskan konstruk variabel penelitian yaitu, Kecerdasan Interpersonalonal, OCB Guru, dan Sikap Profesi Keguruan. Hasil Uji Confirmatory Factor Analysis
(CFA) memenuhi kriteria apabila Loading Factor atau Standardized Loading Estimate> 0,5. Unidimensionalitas adalah syarat yang diperlukan untuk analisis validitas dan reliabilitas construct (Ferdinand, 2000). Confirmatory Factor Analysis (CFA) dapat digunakan untuk memeriksa unidimensionalitas dari sebuah variabel. Nilai minimal yang diharapkan untuk GFI adalah 0,90 (Hair, 1995). Bila hasil perhitungan GFI lebih besar dari 0,90 berarti indikator telah memiliki reliabilitas yang bisa diterima. Berikut hasil yang berhubungan dengan kelima variabel yang ada pada penelitian ini.

\section{CFA Kecerdasan Interpersonal $\left(X_{1}\right)$}

Kecerdasan Interpersonal $\left(\mathrm{X}_{1}\right)$ terdiri atas delapan indikator. Tabel menunjukkan hasil Confirmatory Factor Analysis (CFA) pada analisis unidimensionalitas yang ada pada Kecerdasan Interpersonal $\left(\mathrm{X}_{2}\right)$.

Tabel 2. Hasil Uji Normalitas dan Multivariate

\begin{tabular}{lllllll}
\hline Variable & min & max & skew & c.r. & kurtosis & c.r. \\
\hline Y25 & 18,000 & 30,000 &, 051 &, 215 &,- 222 &,- 465 \\
Y24 & 18,000 & 30,000 &,- 060 &,- 251 &, 687 & 1,438 \\
Y23 & 17,000 & 30,000 &, 283 & 1,186 &,- 034 &,- 071 \\
Y22 & 18,000 & 30,000 &, 135 &, 565 &,- 171 &,- 359 \\
Y21 & 18,000 & 30,000 &, 018 &, 075 &,- 426 &,- 891 \\
Y15 & 18,000 & 30,000 &,- 068 &,- 286 &,- 547 & $-1,145$ \\
Y14 & 17,000 & 30,000 &, 278 & 1,162 &,- 211 &,- 442 \\
Y13 & 16,000 & 30,000 &, 117 &, 489 &,- 126 &,- 264 \\
Y12 & 18,000 & 30,000 &, 354 & 1,479 &, 162 &, 338 \\
Y11 & 8,000 & 30,000 & $-1,554$ & $-6,499$ & 8,392 & 17,552 \\
X31 & 22,000 & 40,000 &, 057 &, 239 &, 492 & 1,030 \\
X32 & 23,000 & 40,000 &, 090 &, 378 &, 848 & 1,773 \\
X33 & 20,000 & 39,000 &,- 430 & $-1,797$ &, 891 & 1,863 \\
X21 & 30,000 & 50,000 &, 127 &, 532 &, 233 &, 487 \\
X22 & 27,000 & 45,000 &, 257 & 1,077 &,- 139 &,- 292 \\
X23 & 26,000 & 50,000 &, 364 & 1,522 & 1,067 & 2,233 \\
X24 & 33,000 & 55,000 &, 033 &, 139 &, 782 & 1,635 \\
X11 & 21,000 & 40,000 &,- 088 &,- 368 &, 869 & 1,818 \\
X12 & 20,000 & 37,000 &,- 976 & $-4,082$ & 2,108 & 4,409 \\
X13 & 15,000 & 40,000 &,- 754 & $-3,154$ & 2,348 & 4,910 \\
Multivariate & & & & & 91,565 & 15,814 \\
\hline
\end{tabular}

Tabel 3. Hasil Uji Convergent Validity Kecerdasan Interpersonal $\left(X_{I}\right)$

\begin{tabular}{llll}
\hline Indikator & $\begin{array}{l}\text { Factor } \\
\text { Loading }\end{array}$ & C.R. & Keterangan \\
\hline Kepekaan social (Social Sensitivity) $\mathrm{X}_{1}$ & 0,920 & 3,983 & Signifikan \\
Pandangan Sosial (Social Insight) $\mathrm{X}_{2}$ & 0,850 & 5,425 & Signifikan \\
Komunikasi social (SocialCommunication) $\mathrm{X}_{3}$ & 0,860 & 5,510 & Signifikan \\
\hline
\end{tabular}


Berdasarkan Tabel 3 diketahui bahwa semua indikator Kecerdasan Interpersonal $\left(\mathrm{X}_{2}\right)$ mempunyai nilai standardized regression weight (nilai lambda) lebih besar dari 0,50 dan nilai C.R. $>2,00$, sehingga dapat dipastikan bahwa seluruh indikator Kecerdasan Interpersonal $\left(\mathrm{X}_{2}\right)$ telah memenuhi syarat validitas konstruks.

\section{OCB Guru(Y1)}

OCB Guru $\left(\mathrm{Y}_{1}\right)$ dapat diukur dari lima indikator, yaitu Altruisme $\left(\mathrm{Y}_{1.1}\right)$, Courtesy ( $\left.\mathrm{Y}_{1.2}\right)$, Conscientiousnes $\left(\mathrm{Y}_{1.3}\right)$, Sportmanship $\left(\mathrm{Y}_{1.4}\right)$, Civic Virtue $\left(\mathrm{Y}_{1.5}\right)$. Seluruh perhitungan hasil analisis unidimensionalitas OCB Guru $\left(\mathrm{Y}_{1}\right)$ telah memenuhi syarat confirmatory factor analysis walaupun ada beberapa yang marjinal. Nilai GFI sebagai ukuran kelayakan dari model mencapai nilai 0,924 (lebih besar dari 0,90). Nilai chi square sebesar 22,438 menghasilkan nilai probabilitas sebesar 0,000. Dengan demikian, tidak terdapat perbedaan antara matrik kovarian sampel dengan matrik kovarian populasi yang diestimasikan, yang berarti model adalah fit. Oleh karena itu dapat disimpulkan bahwa telah ada bukti apabila OCB Guru $\left(\mathrm{Y}_{1}\right)$ berdasarkan lima indikator memiliki unidimensinalitas yang dapat diterima. Berdasarkan nilai factor loading, seluruh indikator bernilai di atas 0,50 dengan kisaran 0,680,81 sehingga juga memberikan bukti bahwa setiap indikator memiliki tingkat validitas yang tinggi terhadap OCB Guru $\left(\mathrm{Y}_{1}\right)$. Dapat disimpulkan bahwa lima indikator OCB Guru (Y1) memiliki unidimensionalitas yang dapat diterima. Selanjutnya dilakukan pengujian Convergent validity dan construct reliabilit $y$ untuk mengetahui valititas konstruk dan reliabilitas konstruk. Rekap hasil pengujian disajikan pada tabel 4 .

Tabel 4. Hasil Uji Convergent Validity OCB Guru (Y1)

\begin{tabular}{llll}
\hline Indikator & $\begin{array}{l}\text { Factor } \\
\text { Loading }\end{array}$ & C.R. & Keterangan \\
\hline Altruisme $\left(Y 1_{.1}\right)$ & 0,700 & 5,816 & Signifikan \\
Courtesy $\left(Y 1_{.2}\right)$ & 0,810 & 4,636 & Signifikan \\
Conscientiousnes $\left(Y 1_{.3}\right)$ & 0,690 & 5,761 & Signifikan \\
Sportmanship $\left(Y 1_{.4}\right)$ & 0,770 & 5,161 & Signifikan \\
Civic Virtue $(Y 1.5)$ & 0,680 & 6,093 & Signifikan \\
\hline
\end{tabular}

Berdasarkan Tabel 4 diketahui bahwa semua indikator OCB Guru $\left(\mathrm{Y}_{1}\right)$ mempunyai nilai standardized regression weight (nilai lambda) lebih besar dari 0,50 dan nilai C.R. $>2,00$, sehingga dapat dipastikan bahwa seluruh indikator OCB Guru $\left(\mathrm{Y}_{1}\right)$ telah memenuhi syarat validitas konstruks. Hasil model pengukuran masing-masing indikator OCB Guru $\left(\mathrm{Y}_{1}\right)$ adalah sebagai berikut :

$\begin{array}{ll}\text { Altruisme }\left(Y 1_{.1}\right) & =0,700 \mathrm{Y} 1 \\ \text { Courtesy }\left(Y 1_{.2}\right) & =0,810 \mathrm{Y} 1 \\ \text { Conscientiousnes }\left(Y 1_{.3}\right) & =0,690 \mathrm{Y} 1 \\ \text { Sportmanship }\left(Y 1_{4}\right) & =0,770 \mathrm{Y} 1 \\ \text { Civic Virtue }\left(Y 1_{.5}\right) & =0,680 \mathrm{Y} 1\end{array}$

\section{CFA Sikap Profesi Guru( $\left.\mathrm{Y}_{2}\right)$}

Sikap Profesi Guru (Y2) terdiri atas tujuh indikator, dengan hasil Confirmatory Factor Analysis (CFA) pada analisis unidimensionalitas terhadap Sikap Profesi Guru $\left(\mathrm{Y}_{2}\right)$. Berikutnya, Sikap Profesi Guru $\left(\mathrm{Y}_{2}\right)$ dapat diukur dari delapan indikator, yaitu Altruism $\left(\mathrm{Y}_{2 \cdot 1}\right)$, Courtesy $\left(\mathrm{Y}_{2 \cdot 1}\right)$, Sportmanship $\left(\mathrm{Y}_{2 \cdot 1}\right)$, Civic Virtue $\left(\mathrm{Y}_{2 \cdot 1}\right)$, Conscientiousness $\left(\mathrm{Y}_{2 \cdot 1}\right)$,. Seluruh perhitungan hasil analisis unidimensionalitasSikap Profesi Guru (Y2) telah memenuhi syarat confirmatory factor analysis walaupun ada beberapa yang marjinal. Nilai GFI sebagai ukuran kelayakan dari model mencapai nilai 0,891 (lebih besar dari 0,90). Nilai chi square sebesar 58,257 menghasilkan nilai probabilitas sebesar 0,000 . Dengan demikian, tidak terdapat perbedaan antara matrik kovarian sampel dengan matrik kovarian populasi yang diestimasikan, yang berarti model adalah fit. Oleh karena itu dapat disimpulkan bahwa telah ada bukti apabila Sikap Profesi Guru (Y2) berdasarkan delapan indikator memiliki unidimensinalitas yang dapat diterima.Berdasarkan nilai factor loading, indikator yang bernilai di atas 0,50 dengan kisaran 0,77 - 0,88 dan indikator $\mathrm{Y}_{26}$ bernilai $-0,50$ dan $\mathrm{Y}_{27}$ bernilai 0,46 sehingga juga memberikan bukti bahwa mayoritas indikator memiliki tingkat validitas yang tinggi terhadap Sikap Profesi Guru $\left(Y_{2}\right)$. Oleh karena itu, dapat disimpulkan bahwa lima indikator Sikap Profesi Guru $\left(Y_{2}\right)$ memiliki unidimensionalitas yang dapat diterima dan 2 indikator tidak diterima yaitu selanjutnya dilakukan pengujian Convergent validity dan construct reliability untuk mengetahui valititas konstruk dan reliabilitas konstruk. Rekap hasil pengujian disajikan pada tabel 5 .

Dipublikasikan Oleh :

UPT Publikasi dan Pengelolaan Jurnal

Universitas Islam Kalimantan Muhammad Arsyad Al-Banjari Banjarmasin 
M. Yuliansyah, I Nyoman Sujana Degeng, Bambang Budi Wiyono, dan Achmad Supriyanto Jurnal Bimbingan dan Konseling Ar-Rahman

Volume 4, Nomor 2, Tahun 2018

e-ISSN 2477-6300

Tabel 5. Hasil Uji Convergent Validity Sikap Profesi Guru (Y2)

\begin{tabular}{llll}
\hline Indikator & $\begin{array}{l}\text { Factor } \\
\text { Loading }\end{array}$ & C.R. & Keterangan \\
\hline Terhadap Peraturan Perundang-undangan (Y2.1) & 0,770 & 6,073 & Signifikan \\
Terhadap Organisasi Profesi (Y2.2) & 0,880 & 4,584 & Signifikan \\
Terhadap teman sejawat (Y2.3) & 0,770 & 6,088 & Signifikan \\
Terhadap anak didik (Y2.4) & 0,790 & 5,850 & Signifikan \\
Terhadap tempat kerja (Y2.5) & 0,790 & 5,938 & Signifikan \\
Terhadap Pemimpin (Y2.6) & 0,460 & 6,991 & Signifikan \\
Terhadap pekerjaan (Y2.7) & -050 & 7,209 & Signifikan \\
\hline
\end{tabular}

Tabel 6. Evaluasi Kriteria Indeks-Indeks Keseuaian Model Struktural (Model Evaluasi)

\begin{tabular}{llll}
\hline \multicolumn{1}{c}{ Kriteria } & \multicolumn{1}{c}{ Hasil } & Nilai Kritis & Evaluasi Model \\
\hline Chi-square $\left(\square^{2}\right)$ & 184,001 & $\square 1210,796$ & Baik \\
Probabilitas & 0,035 & $\square 0,05$ & Baik \\
Derajat Bebas & 151 & - & - \\
GFI & 0,862 & $\square 0,90$ & Baik \\
RMSEA & 0,046 & $\square 0,08$ & Baik \\
CMIN/DF & 1,219 & $\square 2,00$ & Baik \\
AGFI & 0,808 & $\square 0,90$ & Marjinal \\
CFI & 0,982 & $\square 0,90$ & Baik \\
TLI & 0,977 & $\square 0,90$ & Baik \\
\hline
\end{tabular}

Evaluasi Kriteria Kelayakan Model (Goodness of Fit Model)

Penggunaan Structural Equation Modeling (SEM) untuk menguji berbagai hubungan dalam suatu model berguna menganalisis, mengevaluasi validitas, dan kausalitas antar variabel dari model ini digunakan software AMOSVersi 20.

Tabel 6 menunjukkan ringkasan hasil yang diperoleh dalam analisis dan nilai yang direkomendasikan untuk mengukur kelayakan model. Hasil analisis yang terkait dengan indeks kelayakan model menerangkan bahwa evaluasi model menghasilkan nilai kelayakan yang lebih baik dari pada model awal. Kelayakan model telah memenuhi seluruh syarat kelayakan termasuk pada hasil uji Chi Square. Model akan diterima, apabila model sesuai dengan data, yaitu nilai $p$ chi Square lebih besar dari 0,05 pada tingkat signifikan 0,05 . Model evaluasi pada penelitian ini dapat diterima sebagai model akhir untuk dilakukan interpretasi dan uji hipotesis. Pengujian model pengukuran berhubungan dengan lima variable laten yaitu: , Kecerdasan Interpersonal, , OCB Guru dan Sikap Profesi keguruandengan menggunakan 24 indikator. Berikut hasil uji yang berhubungan dengan model pengukuran.

\section{Pengujian Hipotesis Model Persamaan Struktural}

Berdasarkan hasil analisis model persamaan struktural Kecerdasan Interpersonal $\left(\mathrm{X}_{2}\right)$, OCB Guru $\left(\mathrm{Y}_{1}\right)$, terhadap Organizational Citizenship Behavior $\left(\mathrm{Y}_{1}\right)$ Pengujian hipotesis dapat dilihat pada Tabel 7 berikut. 
Tabel 7. Hasil Uji Koefisien Regresi Pengaruh Antar Variabel

\begin{tabular}{lllllll}
\hline No & Variabel & & Koef. & CR & PValue & Ket. \\
\hline 1 & Kecerdasan & Interpersonalonal (X1) & 0,023 & 0,259 & 0,796 & Tidak \\
& OCB (Y1) & & $0,25 n i f i k a n$ \\
2 & Kecerdasan Interpersonalonal (X2) $\square$ & 0,524 & 6,546 & 0,351 & Signifikan \\
& $\begin{array}{l}\text { Sikap Profesi Guru (Y) } \\
3\end{array}$ & $\begin{array}{l}\text { OCB Guru (Y1) } \\
\text { (Y2) Sikap Profesi Guru }\end{array}$ & 0,172 & 1,627 & 0,041 & Signifikan \\
\hline
\end{tabular}

Berdasarkan Tabel 7 di atas dapat dijelaskan hasil pengujian hipotesis sebagai berikut :

1. Hipotesis satu $\left(\mathrm{H}_{1}\right)$ menyatakan bahwa Kecerdasan Interpersonal berpengaruh signifikan terhadap Organizational Citizenship Behavior (OCB). Koefisien jalur yang bertanda positif sebesar 0,023 dengan nilai C.R. sebesar 0,259 lebih kecil dari 2, dan nilai probabilitas sebesar $0,796>\alpha$ sebesar 5\%, artinya Kecerdasan Interpersonaltidak berpengaruh signifikan terhadap Organizational Citizenship Behavior (OCB) jadi hipotesis dua $\left(\mathrm{H}_{2}\right)$ ditolak, artinya Kecerdasan Interpersonaltidak berpengaruh signifikan terhadap Organizational Citizenship Behavior (OCB).

2. Hipotesis lima $\left(\mathrm{H}_{5}\right)$ menyatakan bahwa Kecerdasan Interpersonalonal berpengaruh terhadap sikap Profesi Guru. Koefisien jalur yang bertanda positif sebesar 0,524 dengan nilai C.R. sebesar 6,546 lebih kecil dari 2, dan nilai probabilitas sebesar $0,351<\alpha$ sebesar $5 \%$, artinya

Kecerdasan Interpersonalonalberpengaruh signifikan terhadap sikap Profesi Guru.Jadi hipotesis lima $\left(\mathrm{H}_{5}\right)$ dterima, artinya Kecerdasan Interpersonalonal berpengaruh secara signifikan terhadap sikap Profesi Guru.

3. Hipotesis tujuh $\left(\mathrm{H}_{7}\right)$ menyatakan bahwa $\mathrm{OCB}$ Guru berpengaruh signifikan terhadap Sikap Profesi Guru. Koefisien jalur yang bertanda positif sebesar 0,172 dengan nilai C.R. sebesar 1,627 lebih kecil dari 2, dan nilai probabilitas sebesar $0,041<\alpha$ sebesar 5\%, artinya OCB Guru berpengaruh signifikan terhadap Sikap Profesi Guru. Jadi hipotesis tujuh $\left(\mathrm{H}_{7}\right)$ diterima, artinya OCB Guru berpengaruh secara signifikan terhadap Sikap Profesi Guru.

\section{PEMBAHASAN}

1. Hubungan antara Kecerdasan Interpersonal dengan Sikap Profesi Keguruan

Variabel kecerdasan Interpersonal pada Guru

MTSN se Kota Banjarmasin memiliki nilai rerata sebagian responden (138 orang atau 55,87\%) berkategori sedang dan sebagian lagi responden (109 responden atau 44,13\%) berkategori tinggi. Temuan statistik deskriptif ini sangat positif, karena hal ini menunjukkan bahwa sebagian besar guru-guru MTSN se Kota Banjarmasin merasa bahwa kecerdasan Interpersonal adalah sebagai suasana batin dalam diri seseorang guru untuk melakukan aktifitas demi mencapai tujuan, terutama dalam hal melaksanakan tugas mengajar dan tugas tambahan lainnya.

Sesuai dengan teori Carlaw, Deming \& Friedman (2003) menyatakan bahwa kecerdasan Interpersonal yang tinggi adalah karyawan yang bekerja dengan berenergi, antusias, dan memiliki rasa kebersamaan, sebaliknya karyawan yang memiliki kecerdasan Interpersonal rendah adalah ketika karyawan merasa bosan, berkecil hati dan malas. Kecerdasan Interpersonal ditunjukkan dengan semangat, antusiasme dan kepercayaan pada kebijakan organisasi, program dan tujuan organisasi. Tingginya persepsi ternang pentingnya kecerdasan Interpersonal ini diduga dapat meningkatkan Sikap Profesi Keguruan.Temuan penelitian ini menyatakan bahwa terdapat hubungan langsung yang siginifikan antara Kecerdasan Interpersonal dengan Organizational Citizenship Behavior (OCB) pada guru MTSNse Kota Banjarmasin. Koefisien regresi dan hubungan Kecerdasan Interpersonal dengan Organizational Citizenship Behavior (OCB) pada guru MTSNse Kota Banjarmasin memiliki nilai 0,023 dengan C.R sebesar 0,259 (lebih kecil dari 2,0) dan p-value 0,796 (lebih besar dan 0,05), dan memiliki nilai dalam bentuk koefisien standard sebesar 0,614 . Hal ini menunjukkan bahwa hipotesis nol diterima, karena nilai $\gamma 1 \neq 0$. Dengan demikian, hipotesis penelitian ini menyatakan bahwa tidak terdapat hubungan yang signifikan antara Kecerdasan Interpersonal dengan Organizational Citizenship Behavior (OCB)pada guru MTSNse Kota Banjarmasin adalah dapat diterima.Untuk uji hipotesis kausalitas, dari hasil analisa data diperoleh temuan adanya pengaruh langsung atau efek langsung (direct effect) dari variabel Kecerdasan Interpersonal dengan Organizational Citizenship Behavior (OCB) pada guru dengan nilai sebesar 0,614 . Temuan ini menunjukkan bahwa tinggi rendahnya Kecerdasan Interpersonal guru di MTSNse Kota Banjarmasin tidak dipengaruhi langsung bagaimana derajat kecerdasan interpersonal yang mencerminkan kepribadian yang mantap, stabil, dewasa, arif dan berwibawa, menjadi tauladan bagi

Dipublikasikan Oleh :

UPT Publikasi dan Pengelolaan Jurnal

Universitas Islam Kalimantan Muhammad Arsyad Al-Banjari Banjarmasin 
peserta didik dan berakhlak mulia yang menjadi kontinum Kecerdasan Interpersonal dengan Organizational Citizenship Behavior (OCB) pada guru bisa dimiliki, diyakini dan dilakukan oleh guru. Makin baik perilaku Kecerdasan Interpersonal yang dimiliki seorang guru, maka akan meningkatkan Organizational Citizenship Behavior (OCB) yang besar bagi guru-guru, yang pada akhirnya akan meningkatkan pencapaian tujuan pengajaran.

Temuan hasil penelitian ini sesuai dengan hasil penelitian Anggraini (2008) bahwa perilaku kepemimpinan berpengaruh secara signifikan terhadap kecerdasan Interpersonal karyawan perkebunan widodaren. Secara simultan perilaku kepemimpinan berorientasi tugas dan perilaku kepemimpinan berorientasi hubungan berpengaruh terhadap kecerdasan Interpersonal karyawan.

Temuan hasil penelitian ini juga mernperkuat penelitian terdahulu bahwa kecerdasan Interpersonal guru akan muncul bila kecerdasan interpersonal sudah baik. Seorang guru menerapkan hubungan vertikal ke bawah yaitu seorang guru menjalin hubungan baik terhadap semua bawahan yaitu kepada guru dan staff, hal ini dilakukan agar mereka bersedia melaksanakan tugas-tugas dengan sebaik-baiknya, memupuk kesetiaan dan tanggung jawab kepada teman sekerja, tugas dan tempat kerja. Seorang guru juga melakukan pendekatan-pendekatan untuk meningkatkan daya kreasi, inisiatif yang tinggi untuk mendorong semangat bawahannya.Untuk memberikan kecerdasan Interpersonal guru dalam melaksanakan tugas dengan baik, seorang guru harus memperhatikan kecerdasan Interpersonal guru dan profesionalisme guru untuk menghasilkan prestasi kerja kerja di sekolah. Upaya tersebut dilakukan dengan menjalin komunikasi yang harmonis diantara personel sekolah, memberi dukungan dan kepedulian serta kepercayaan terhadap pekerjaan guru, menghormati pekerjaan guru, menciptakan keterpaduan antara program pembelajaran sekolah dengan praktik pembelajaran guru di kelas, dan menciptakan pembaharuan praktik pembelajaran guru. Peningkatan kecerdasan Interpersonal guru membantu siswa belajar sehingga dapat mengembangkan pengetahuan, keterampilan, sikap, dan nilai akademik siswa.Untuk mengefektifkan program pembelajaran, seorang guru membentuk kelompok atau tim penasehat guru yang berfungsi untuk memberi masukan kepada seorang guru tentang praktik pembelajaran yang diterapkan dan membantu memecahkan persoalan pembelajaran sebelum dibawa ke rapat dewan guru. Tim ini terdiri dari guru senior yang memiliki kompetensi sesuai bidangnya.Peningkatan Sikap Profesi Keguruan dilakukan seorang guru melalui berbagai teknik pembinaan profesionalisme guru. Tujuan utamanya adalah membantu guru memperbaiki klemampuan

mengajarnya sehingga dapat memperbaiki pembelajaran siswa. Teknik supervisi tersebut bersifat Individual dan kelompok, yang meliputi: kunjungan kelas, pertemuan pribadi, rapat rutin, kunjungan antar sekolah, pertemuan dalam kelompok kerja, serta pelatihan dan penataran.Keberhasilan tugas guru sebagai tenaga pendidik dalam mengemban amanat tujuan pendidikan dipengaruhi banyak faktor, salah satunya adalah faktor kecerdasan Interpersonal. Tinggi rendahnya kecerdasan Interpersonal, sangat berpengaruh terhadap produktivitas kerja yang dapat dicapai oleh seorang petugas dalam bidang tertentu. Kecerdasan Interpersonal yang tinggi dari guru dimanifestasikan dalam bentuk kreativitas dan inisiatif dalam menyelenggarakan proses pembelajaran. Moekjizat (2003:155) berpendapat bahwa kecerdasan Interpersonal atau moril adalah kemampuan sekelompok orang untuk bekerjasama menekan dengan tegas hakekat saling hubungan dan suatu kelompok dengan suatu keinginan yang nyata untuk bekerja sama. Seorang guru dapat dikatakan memiliki kecerdasan Interpersonal yang tinggi apabila merasa puas terhadap pekerjaannya, semangat, rasa tanggungjawab dan antusiasme. Semangat kerja merupakan sikap atau tingkah laku sekelompok orang tuituk bekerja sama dengan giat dan konsekuen dalam mencapai tujuan dengan penult tanggung jawab dan disiplin, sehingga pekerjaan dapat terlaksana dengan mudah, dapat tercapai apa yang menjadi tujuannya. Tenaga kerja yang dibutuhkan sekolah adalah tenaga kerja yang mempunyai kecerdasan Interpersonal yang tinggi. Menurut Pariata Westra (2000:72) kecerdasan Interpersonal adalah sikap dari individu maupun kelompok terhadap lingkungan kerjanya dan terhadap kesukarelaan untuk bekerjasama sesuai dengan kebutuhan utama organisasi". Kecerdasan Interpersonal yang tinggi memberi kesetiaan, kewajiban, disiplin, inisiatily dan kebanggaan terhadap sekolah. Seorang guru akan lebih bersemangat bila mengetahui pekerjaan yang dilakukan mempunyai arti penting dan menarik perhatian. Sebagai contoh seorang guru akan lebih bersemangat dalam melakukan pekerjaan apabila mereka mendapatkan kecerdasan interpersonal, profesionalisme dan penghargaan kerja sesuai dengan apa yang mereka berikan kepada sekolah.

Menurut Alex S. Nitisetnito (2002:96) kecerdasan Interpersonal adalah melakukan pekerjaan secara lebih giat sehingga dengan demikian pekerjaan akan dapat diharapkan lebih cepat dan lebih baik. Semangat ini terjalin dalam semangat golongan yaitu suatu rasa kesedihan yang terdapat di dalam golongan pegawai yang sama-sama bekerja dan semangat ini menentukan apakah antara yang satu sama yang lain suka bekerja bersama-sama dalam mencapai tujuan yang sama. Kecerdasan Interpersonal dipengaruhi 
oleh berbagai faktor diantaranya adalah prestasi kerja dan kecerdasan interpersonal, keduanya mempunyai peranan yang sangat penting dalam menumbuhkan kecerdasan Interpersonal guru. Menurut Nurkolis (2006:153),"prestasi kerja merupakan proses mempengaruhi dalam menentukan tujuan organsisasi, mekecerdasan Interpersonal perilaku-perilaku pengikut untuk mencapai tujuan" prestasi kerja yang dimaksud adalah prestasi kerja guru sebagai suatu jabatan yang bertanggung jawab penuh atas berjalannya dan terlaksananya tujuan organisasi. Dalam esensinya, prestasi kerja adalah upaya pencapaian tujuan dengan dan melalui orang-orang sehingga seorang profesionalisme harus memperhatikan hubungan antara tugas dengan guru yang ditujukan agar mempunyai gairah atau semangat untuk melaksanakan pekerjaan dengan senang hati, hal inilah yang akan mendorong tercapainya tujuan organisasi. Kondisi yang terlihat dalam semangat atau gairah kerja yang menghasilkan kegiatan kerja sebagai kontribusi bagi tercapainya tujuan organisasi dipengaruhi pula oleh kecerdasan Interpersonal, karena dengan sernangat kerja yang tersedia dapat memudahkan dan rnemperlancar pelaksanaan pekerjaan kegiatan belajar mengajar.

\section{Kecerdasan Interpersonal dengan $\mathrm{OCB}$ guru}

Untuk variabel OCB Guru dalam menghasilkan temuan nilai rerata sebagian responden (146 orang atau $59,11 \%$ ) berkategori sedang dan sebagian lagi responden (101 responden atau 40,89\%) berkategori tinggi. Temuan statistik deskriptif ini sangat positif, karena sebagian besar guru-guru MTSN se Kota Banjarmasin merasa memiliki OCB Guruberdampak pada peningkatan kecerdasan Interpersonal. berprestasi yang tinggi, mengingat keberadaan OCB Gurumerupakan sikap Interpersonalonal yang menyenangkan dan mencintai pekerjaannya, reaksi personal dan dinamis melekat pada guru sehingga mempunyai menimbulkan suatu keadaan diri yang baik dan siap sebagai seorang guru untuk berprestasi.

Sesuai dengan teori yang dikembangkan oleh Herzberg, yang membedakan antara faktor-faktor penyebab OCB Gurudisebut motivator diantaranya adalah: prestasi, pengakuan, karakteristik atau kondisi pekerjaan itu sendiri, tanggung jawab. Faktor-faktor penyebab ketidakpuasan kerja disebut hygiene antara lain: supervisi, kondisi, kerja, gaji, dan keselamatan kerja. Menurut teori ini, apabila faktor-faktor kepuasan atau motivator terpenuhi akan memberikan kepuasan, tetapi apabila tidak terpenuhi, tidak selalu menimbulkan kepuasan, tetapi apabila tidak terpenuhi akan menimbulkan ketidakpuasan. Kondisi tingginya OCB Guru ini diduga dapat meningkatkan Sikap Profesi Keguruan.
Temuan penelitian ini menyatakan bahwa tidak terdapat hubungan langsung yang signifikan antara kecerdasan Interpersonal dengan Sikap Profesi Keguruan pada guru MTSNse Kota Banjarmasin. Koefisien regresi dari kecerdasan Interpersonal dengan kinerja pada guru MTSNse Kota Banjarmasin memiliki nilai 0,524 dengan C.R sebesar 6,546 (lebih besar dari 2,0) dan p-value *** (lebih kecil dari 0,05 ), dan memiliki nilai dalam bentuk koefisien standard sebesar 0,161 . Hal ini menunjukkan bahwa hipotesis nol diterima, karena nilai $\gamma 3 \neq 0$. Dengan demikian, hipotesis penelitian ini menyatakan bahwa tidak terdapat hubungan yang signifikan antara kecerdasan Interpersonal dengan Sikap Profesi Keguruan pada guru MTSNse Kota Banjarmasin adalah dapat diterima.

Untuk uji hipotesis kausalitas, dari hasil analisa data diperoleh temuan tidak adanya pengaruh langsung atau efek langsung (direct effect) dari variabel kecerdasan Interpersonal dengan kinerja dengan nilai sebesar 0,524. Kecerdasan Interpersonal menggambarkan perasaan senang individu atau kelompok yang mendalam dan puas terhadap pekerjaan, kerja sama, dan lingkungan kerja serta mendorong mereka untuk pekerja secara lebih baik dan produktif. Kecerdasan Interpersonal sangat penting bagi organisasi, maka pekerjaan yang diberikan atau ditugaskan kepadanya akan dapat diselesaikan dengan waktu yang lebih singkat atau lebih cepat, sehingga dapat meningkatkan Sikap Profesi Keguruan. Kecerdasan Interpersonal diduga mempunyai hubungan secara langsung dengan kinerja seorang guru.Temuan ini menunjukkan bahwa tinggi rendahnya kinerja pada guru MTSNse Kota Banjarmasin tidak dipengaruhi langsung bagaimana kecerdasan Interpersonal seorang guru. Makin baik kecerdasan Interpersonal yang dimiliki seorang guru, maka akan meningkatkan kinerja bagi guru-guru MTSNse Kota Banjarmasin. Hal ini dapat dijelaskan bahwa guru dapat bekerja dengan baik, bila kinerja mereka sangat baik.

Temuan hasil penelitian ini sesuai dengan penelitian yang dilakukan oleh Winda (2008) kecerdasan Interpersonal adalah kesediaan perasaan yang memungkinkan seseorang bekerja untuk menghasilkan kerja lebih banyak dan lebih baik. Namun kecerdasan Interpersonal menggambarkan perasaan senang individu atau kelompok yang mendalam dan puas terhadap pekerjaan, kerja sama, dan lingkungan kerja serta mendorong mereka untuk bekerja secara lebih baik dan produktif.Temuan penelitian Hartati (2011) dalam penelitiannya penelitian menunjukkan tidak ada hubungan positif antara kecerdasan Interpersonal dengan Sikap Profesi Keguruan SD Negeri Se-Kecamatan Daha Selatan, serta ada hubungan positif dengan Sikap Profesi 
Keguruan SD Negeri Se-Kecamatan Daha Selatan juga ada hubungan poisitif secara simultan antara kecerdasan Interpersonal dan disiplin dengan Sikap Profesi Keguruan SD Negeri Se-Kecamatan Daha Selatan.

Temuan Nurbayah (2009), menyatakan pengaruh pendidikan dan pelatihan, kecerdasan Interpersonal dan kompetensi guru terhadap profesionalisme Guru MTSN Negeri 2 Banjarbaru. Hasil dan penelitian ini menjelaskan adanya pengaruh yang cukup signifikan dilihat dari pengaruh parsial maupun simultan.

Temuan Sondakh (2010) dengan hasil penelitian ini menunjukkan terdapat perbedaan kecerdasan Interpersonal guru berdasarkan perilaku kepemimpinan kepala MTSN Negeri di Kabupaten Barito Selatan.Hasil penelitian di atas menunjukkan bahwa terdapat pengaruh signifikan dan kecerdasan Interpersonal terhadap Sikap Profesi Keguruan. Menurut Nitisemito (2005: 61) bila seorang guru telah memiliki kecerdasan Interpersonal maka secara otomatis kecerdasan Interpersonal tersebut akan berdampak pada peningkatan Sikap Profesi Keguruan, dengan kata lain kecerdasan Interpersonal memiliki hubungan yang positif terhadap Sikap Profesi Keguruan. Hasil penelitian ini sesuai dengan penelitian yang dilakukan oleh Yuniari (2009: 90), hasil penelitiannya menunjukkan kecerdasan Interpersonal secara signifikan mempengaruhi kinerja karyawan, yang menemukan bahwa kecerdasan Interpersonal secara langsung memiliki pengaruh signifikan terhadap kinerja karyawan, semakin tinggi kecerdasan Interpersonal yang dimiliki karyawan meliputi tingkat absensi yang rendah maka kinerja karyawan akan mengalami peningkatan.

Seorang guru yang dengan perilaku kepemimpinannya selalu memonitor dalam pelaksanaan pembelajaran yang dilakukan guru dengan memotivasi guru akan menyebabkan guru dengan semangat melaksanakan interaksi belajarmengajar, melaksanakan evaluasi, dan bahkan guru akan lebih menguasai bahan ajar akademik. Dengan kata lain, terdapat kontribusi yang tinggi antara pelaksanaan kecerdasan interpersonal terhadap Sikap Profesi Keguruan. Semakin tinggi mangat kerja guruguru semakin tinggi pula kinerjanya. Ini berarti bahwa untuk dapat meningkatkan Sikap Profesi Keguruanguru, maka peningkatan kecerdasan Interpersonal guru perlu dilakukan baik oleh guru itu sendiri maupun dari seorang guru dan lingkungan kerja.

Dengan demikian dapat dikatakan bahwa kecerdasan Interpersonal merupakan faktor penting dalam ripaya peningkatan kinerja Baru. Bertitik tolak dari temuan tersebut, jelaslah bahwa kecerdasan Interpersonal berpengaruh terhadap Sikap Profesi Keguruan. Guru yang memiliki kecerdasan

Interpersonal tinggi akan senantiasa bekerja dengan maksimal, menaati apa yang menjadi peraturan sekolah dan berusaha menunjukkan yang terbaik bagi sekolahnya serta memiliki tanggungjawab yang besar atas tugas-tugasnya. Kecerdasan Interpersonal yang tinggi juga akan mendorong guru mengembangkan kreativitas dari mengaktualkan semua kemampuan serta energi yang dimilikinya demi mencapai prestasi yang maksimal.

\section{Hubungan OCB guru dengan Sikap Profesi Keguruan}

Kondisi Sikap Profesi Keguruan pada MTSN se Kota Banjarmasin ditunjukan oleh hasil analisis statistik deskriptif dengan nilai rerata sebagian kecil responden ( 51 orang atau $20,65 \%$ ) berkategori sedang dan sebagian besar responden (196 responden atau $79,35 \%$ ) berkategori tinggi. Temuan statistik deskriptif ini menunjukan bahwa sebagian besar guruguru MTSN se Kota Banjarmasin memiliki kinerja yang tinggi yang diukur menggunakan empat dimensi kinerja. Sesuai dengan teori T.R Mitchell (Rusman, 2009:319) bahwa kinerja mempunyai empat dimensi. yaitu: (a) quality of work (kualitas kerja), (b) promptness (ketepatan kerja), (c) initiative (inisiatif), dan (d) communication (komunikasi).

Sahertian (dalam Rusman, 2009:319) menjelaskan bahwa standar Sikap Profesi Keguruan itu berhubungan dengan kualitas guru dalam menjalankan tugasnya, seperti: (a) bekerja dengan siswa secara individual, (b) persiapan dan perencanaan pembelajaran, (c) pendayagunaan media pembelajaran, (d) melibatkan siswa dalam berbagai pengalaman belajar dan (f) kepemimpinan yang aktif dari guru. Kondisi tingginya Sikap Profesi Keguruan ini diduga ada hubungannya dengan variabel-variabel lain dalam penelitian ini, yaitu variabel kecerdasan Interpersonaldan OCB Guruyang dimilikinya.Temuan penelitian ini menyatakan bahwa terdapat hubungan langsung yang signifikan antara OCB Gurudengan kinerja pada guru MTSNse Kota Banjarmasin. Koefisien regresi dari OCB Gurudengan Sikap Profesi Keguruan pada guru MTSNse Kota Banjarmasin memilki nilai 0,172 dengan C.R sebesar 1,627 (lebih kecil dari 2,0) dan p-value 0,104 (lebih kecil dari 0,05), dan memiliki nilai dalam bentuk koefisien standard sebesar 0,248. Hal ini menunjukan bahwa hipotesis nol ditolak, karena nilai $\gamma 3 \neq 0$. Dengan demikian, hipotesis penelitian ini menyatakan bahwa terdapat hubungan yang signifikan antara OCB Gurudengan kinerja pada guru MTSNse Kota Banjarmasin adalah dapat diterima.Untuk uji hipotesis kausalitas, dari hasil analisa data diperoleh temuan adanya pengaruh langsung atau efek langsung (direct effect) dari variabel kompetensi paedagogik ke efikasi diri dengan nilai sebesar 0,248. Kemampuan kompetensi paedagogik yang baik akan menyebabkan 
guru dapat bekerja melaksanakan tugas dengan lancar, terhindar dari ganguan dan tekanan, sehingga dapat maksimal dalam melaksanakan tugasnya. Oleh karena itu pemahaman seorang guru terhadap peserta didik untuk mengaktualisasikan berbagai potensi yang dimilikinya akan membuat guru merasa nyaman dalam bekerja, sehingga dapat meningkatkan Sikap Profesi Keguruan. OCB Gurudiduga mempunyai hubungan secara langsung dengan kinerja seorang guru.

Kepuasan dalam menjalankan tugas merupakan hal penting bagi kinerja atau produktivitas seseorang. Suatu gejala yang dapat membuat rusaknya kondisi organisasi sekolah adalah rendahnya kepuasan guru dimana timbul gejala seperti: kemangkiran, malas bekerja, banyaknya keluhan guru, rendahnya prestasi kerja, rendahnya kualitas pengajaran, indisipliner guru, dan lain-lain (Falahy, 2005).Meningkatkan OCB Gurukerja guru merupakan hal yang penting karena menyangkut masalah hasil kerja (kinerja) guru yang merupakan salah satu langkah dalam meningkatkan mutu pelayanan kcpada siswa. Guru dituntut untuk bekerja dengan memberikan pelayanan sebaik-baiknya kepada stakeholder (pemakai sekolah) yaitu siswa, orang tua dan masyarakat.

Hasil ini membuktikan bahwa OCB Guru, dapat mendarong peningkatan Sikap Profesi Keguruan. Temuan ini senada dengan pendapat Wibowo (2007: 324) mengemukakan OCB Gurumerupakan variabel tergantung utama karena menunjukkan dua alasan, yakni: (1) menunjukkan hubungan dengan faktor kinerja; (2) merupakan preferensi nilai yang dipegang banyak peniliti perilaku organisasi. Hubungannya dengan penelitian ini adalah Sikap Profesi Keguruan dipengaruhi oleh kepuasan kerjanya. Terdapatnya hubungan antara OCB Guru dengan Sikap Profesi Keguruan, menunjukkan bahwa guru yang merasa puas dengan hasil pekerjaannya, lingkungan kerjanya, harapan mengenai imbalannya, dorongan yang dialaminya maupun persepsinya akan menunjukkan kinerja yang baik.

Temuan ini menunjukan bahwa tinggi rendahnya kinerja pada guru MTSNse Kota Banjarmasin dipengaruhi langsung bagaimana OCB Guruseorang guru. Makin baik OCB Guruyang dimiliki sarang guru, maka akan meningkatkan kinerja diri bagi guru-guru MTSNse Kota Banjarmasin. Hal ini dapat dipahami karena OCB Gurumerupakan keadaan Interpersonalonal yang menyenangkan dimana para guru memandang pekerjaan mereka dan berdampak positif guru terhadap pekerjaan dan segala sesuatu yang dihadapi dilingkungan kerjanya, penelitian Handoko, (2001). Temuan penelitian Lawler (dalam Steer \& Porter, 1991) sebab seseorang memiliki kepuasan yang tinggi akan memandang pekerjaannya sebagai hal yang menyenangkan, berbeda dengan guru yang memiliki OCB Gururendah, ia akan melihat pekerjaannya sebagai hal yang menjemukan dan membosankan sehingga guru tersebut bekerja dalam keadaan terpaksa.

Sementara menurut Maryani dan Suponto (2001) serta hasil penelitian dari Masrukin dan Waridin (2006) menunjukkan bahwa OCB Gurumempunyai hubungan yang signifikan dengan kinerja individual guru.Temuan Cruden (1988) menyatakan bahwa yang terjadi adalah sebaliknya, yaitu kinerja mengakibatkan kepuasan. Hal ini terjadi berdasarkan pemikiran bahwa dengan kinerja yang baik, guru akan mendapatkan penghargaan seperti promosi, insentif atau perhatian lebih dari atasan, penghargaan tersebut mendorong terjadinya kepuasan kerja, Jadi OCB Gururnerupakan derajat rasa suka atau tidak sukanya tenaga kerja terhadap berbagai aspek pekerjaannya. Antara OCB Gurudapat menyebabkan meningkat Sikap Profesi Keguruan, Masrukin \& Waridin (2006) menyatakan pengaruh OCB Guruterhadap peningkatan kinerja terbukti secara empiris, bahwa OCB Gurumempunyai hubungan signifikan dengan peningkatan kinerja, (Ostroff, 1992) adalah kinerja secara organisasional, bukan kinerja secara individual. Meskipun OCB Guru secara individual pada gilirannya akan meningkatkan kinerja secara organisasional, ada kemungkinan kedua level kinerja tersebut saling bersamaan.

\section{PENUTUP}

Pada akhirnya penelitian ini menyimpulkan bahwa: (1) Terdapat hubungan tidak langsung antara Tingkat KecerdasanInterpersonal dengan Organizational Citizenship Behavior di Madrasah Tsanawiyah Negeri Se- Kota Banjarmasin; (2) Terdapat hubungan langsung antara Kecerdasan Interpersonal dengan Sikap Pada Profesi Keguruan di Madrasah Tsanawiyah Negeri Se- Kota Banjarmasin, dan; (3) Terdapat hubungan antara Sikap Pada Profesi Keguruan dengan Organizational Citizenship Behavior di Madrasah Tsanawiyah Negeri Se- Kota Banjarmasin.

Dengan demikian, Disarankan kepada Kepala Sekolah di MTSN se Kota Banjarmasin untuk memfasilitasi dan memotivasi agar Kecerdasan Interpersonalonal guru yang sudah berkategori tinggi dapat dibina sehingga dapat memperbaiki OCB dan sikap terhadap profesi guru. Selain itu, Disarankan juga kepada para peneliti lain, agar hasil penelitian ini dapat dijadikan sebagai salah satu rujukan dalam mencari bahan kajian dalam penelitannya, dan hasil penelitian ini sebagai pelengkap data-data hasil temuan penelitian yang sudah ada, terkait dengan variabel-variabel Kecerdasan Interpersonalonal, OCB dan Sikap pada Profesi guru. 
M. Yuliansyah, I Nyoman Sujana Degeng, Bambang Budi Wiyono, dan Achmad Supriyanto

Jurnal Bimbingan dan Konseling Ar-Rahman

Volume 4, Nomor 2, Tahun 2018

e-ISSN 2477-6300

\section{REFERENSI}

Aldag, Ray., Reschke, Wayne., (2013). Employee Value Added, New-York, Center for Organizational Effectiveness Inc.

Ali, M. (2015). Analisis Pengaruh Variabel Kepemimpinan terhadap Kinerja Guru Koperasi Unit Desa (KUD) di Kabupaten Sorong. Jurnal Keuangan dan Perhankan. Th. IX. No. 2. Surabaya.

Alimuddin. (2012). Pengaruh Gaya Kepemimpinan terhadap Kinerja Guru Badan Pengawasan Daerah Kota Makassar. Tesis. Program Pasca Sarjana Magister Manajemen Universitas Gajah Mada (tidak dipublikasikan)

Allen, N.J., \& Meyer, J.P. (2012). The measurement and antecedents of affective, continuance, and normative commitment to organization. Journal of occupational psychology. 63, 118

Allison, J. Barbara., Voss, S. Richard., Houston, C. Richard., 2013. An Empirical Investigation of The Impact of $S D B$ on The Relationship Between $O C B$ and Individual Performance., http://www.sbaer.uca.edu/research/2001 /ACME/16 lacme01.htmS

Angle, H., L., \& Perry, J.L. (2013). An empirical assessment of organizational commitment and organizational effectiveness. Administrative Science Quarterly, 27,1-14.

Arikunto, S. (2012). Prosedur Penelitian Suatu Pendekatan Praktik (Edisi Revisi V). Jakarta: Rineka Cipta.

As'ad, M. (2012). Psikologi Industri: Seri Ilmu Sumber Daya Manusia. ed.4. Yogyakarta: Liberty.

As'ad. M. (2013). Perilaku Organisasi: Konsep Dasar dan Aplikasinya. Fisipol UGM: Yogyakarta.

Azwar, S. (2013). Reliabilitas dan Validitas. Edisi ke 3. Yogyakarta: Pustaka Pelajar

Azwar, Saifuddin. (2014). Sikap Manusia Teori dan Pengukurannya, Edisi 2., Pustaka Pelajar., Yogyakarta.

Barnawi \& Arifin, M. (2012). Kinerja Guru Profesional. Yogyakarta: Ar-Ruzz Media.

Bolino, R.A. \& Turnley, W.H. (2013). Going the Extramile: Cultivating and. Managing Employee Citizenship Behavior.

Bolognese, A.F. (2002). Employee resistance to organizational change. Diunduh dari http: // www.newfoundations.com/OrgTheory/Bolo gnese721.html

Bourantas, D. \& Papalexanderis, N. (1993). Differences In Leadership Behavior And
Influence Between Public And Private Organization In Greece. The International Journal of Human-Resources Management. 4:4 December

BPKP. (2000). Pengukuran Kinerja. Suatu Tinjauan pada Instansi Pemerintah. Tim Study Pengembangan Sistem Akuntabilitas Kinerja Instansi Pemerintah. Jakarta.

Brahmana, S.S. \& Sofyandi, H. (2007). Transformational Leadership dan Organization Citizenship Behavior di Utama. Laporan Penelitian. Tidak diterbitkan

Brian Niehoff. tanpa tahun A Motive-Based View of s: Applying an Old Lens to a New Class Organizational Behavior., niehoff@ksu.edu ., Manhattan., Kansas.

Buchanan, B. (2014). Building organizational commitment: the socialization of managers in work organizations. Administrative Science Quarterly, 19, 533-546.

Burton, J., P., Thomas, W,. \& Holtom, B. C. (2012). The Influence of Motivation to Attend. Ability to Atend. and Organizational Commitment on Different Types of Absence Behaviours. Journal of Managerial Issues. p:181-197.

Caldwell, D.F., Chatman, J.A., \& O'Reilly,C.A. (2012). Building organizational commitment: A multifirrn study. Journal of Occupational Psychology, 63, 245-261.

Carlaw, Deming \& Friedman. (2013). Managing \& Motivating Contact Center Employees. USA: The McGraw-Hill Companies.

Chen., L., Y. (2014). Examining The Effect Of Organization Culture And Leadership Behaviors On Organizational Commitment. Job Satisfaction. Adan Job Performance At Small And Middle-Sized Firma Of Taiwan. Journal of American Academy of Business. Sep 2004. 5. V2. 4320438.

Cherniss Carry. (2013). Emotional Intellegence: What and Why Its Matters., http://gwimi.imi.ie/eqhtml/articles what is eq.shtml

Cliffs, S. (2012). Komitmen dan Pengaruhnya terhadap Kinerja Aparatur pada Sekretariat Daerah Kabupaten Kendari. Tesis. Program Pasca Sarjana Magister Manajemen Universitas Gajah Mada (tidak dipublikasikan).

Conger \& Kanungo, J.,A. (2012). Toward a Behavioral Theory of Charismatic Leadership in Organizational Settings". Academy of Management Review. Vol. 12. No. 4. p.637-647

Dipublikasikan Oleh :

UPT Publikasi dan Pengelolaan Jurnal 
M. Yuliansyah, I Nyoman Sujana Degeng, Bambang Budi Wiyono, dan Achmad Supriyanto Jurnal Bimbingan dan Konseling Ar-Rahman Volume 4, Nomor 2, Tahun 2018 e-ISSN 2477-6300

Danim, S. (2012). Transformasi Sumber Daya Manusia. Jakarta: Bumi Aksara

Davis, G., A. \& Thomas, M., A. (2012). Effective School and Effective Teachers. Boston: MA Allyn and Bacon. Inc.

Davis, G., A. (2014). Learning go Teach in the Primary School. London: Hodder and Stoughton.

Depdikbud. Dirjen Didasmen \& Direkturat Dikmenum. 2008. Panduan Manajemen Sekolah SLTP. Jakarta : Deodikbud

Depdiknas RI. (2001). Kamus Umum Bahasa Indonesia. Jakarta: Grarnedia.

Depdiknas. (2004). Standar Kompetensi Guru Sekolah Menengah Pertama. Jakarta: Depdiknas

Dunham, R.B., Grube, J.A., \& Castaneda, M.B. (2013). Organizational commitment: The utility of an integrative definition...Journal of Applied Psychology, 79, 370-380.

Dyne, Van L Cummingetal. (2014). Extra-role behaviors: in pursuit of construct and definitional clarity", Research in Organizational Behavior, Vol. 17 No. 1, pp. 215-85.

Elfina P. Debora. (2013). Pengaruh Kepribadian dan Komitmen Organisasi terhadap Perilaku Citizenship Karyawan., tidak dipublikasikan

Falahy. (2015). Studi Korelasi antara Iklim Organisasi dan Motivasi Berprestasi dengan Kepuasan guru http://www.geocities.,;om/guru valah/tesis falahi bab 2.pdf. 15 Agustus 2018.

Ferdinand, A. (2013). Structural Equation Modeling Dalam Penelitian Manajemen. Badan Penerbit : Universitas Diponegoro.

Forster, Nick. (2015). Maximum Performance : A Practical Guide To Leading And Managing People At Work. Northampton: Edward Elgar Publishing, Inc

Gadot, E.V. (2017). Group-Level in The education system: a Scale Reconstruction and Validation. Educational Administration Quarterly. Vol.XX No.X (XXXX 200X) $\mathrm{XX}-\mathrm{XX}$

Gemmiti, M. (2007). The Relation Between Organizational Commitment, Organizational Identification and . Seminar Paper.

Ghozali, I. (2014). Analisis Multivariat dengan Program SPSS. Badan Penerbit Universitas Diponegoro.

Goleman, Daniel. (2013). Emotional Intelligence. (edisi ke-14). Jakarta: Gramedia. Pustaka Utama
Greenberg, J. \& Baron, R., A. (2013). Behavior in organizations: Understanding and managing the human side of work (5th Ed.). Upper Saddle River. NJ: Prentice Hall.

Griffin, R.,W. (2016). Relationships Among Individual. Task Design. and Leader Behavior Variables. Academy of Management Journal. Vol. 23. No. 4. 665683.

Grusky, D. (2016). Career mobility and organizational commitment. Administrative Science Quartely, 10, 488-503.

Handoko, T., H. (2012). Manajemen Personalia dan Sumber Daya Manusia. Yogyakarta: BPFE.

Handoko. T., H. (2013). Manajemen Personalia dan Sumber Daya Manusia Yogyakarta: BPFE.

Hein, Steve. (2012). Ten Habits of Emotionally Intelligent People, New-York, The EQInstitut Inc.

Hersey, P. \& Kenneth H. B. (2014). Management of Organizational. Behavior. New Jersey: Utilizing Human Recource.

Hoy, W., K. \& Miskel, C., G. (2012). Education Administrasi Theory, Reseach, and Practice. Boston: McCiRaw-Hill.

Hrebeniak, L.G., \& Alutto, J.A. (2012). Personal and role-related factors in the development of organizational commitment. Administrative Science Quarterly, 17, 555-573.

Hrebeniak, L.G. (2013). Effects of job level and participation on employee attitudes and perception of influence. Academy of management journal, 17, 649-662.

Hui, Chun., Simon S.K Lam, Kenneth K.S Law. (2016). Instrumental Values of : a field quasi-experiment, Journal of Applied Psychology, Vol 85 No 5, 8220828

Indra W. (1989). Perilaku Organisasi. Yogyakarta: BPFE.

indriantoro, N. \& Supomo, B. (2012). Metodologi Penelitiaan Bisnis untuk Akuntansi dan Manajemen. Edisi 1. Yogyakarta: BPFE.

Judge \& Bono. (2012). Five-Facto' Model of Personality and Transformational Leadership. Journal Applied Psychology. 85 (5): $751-765$.

Kabul, I. (2015). Kepemimpinan Partisipasif dalam Meningkatkan Prestasi Kerja Anggota Organisasi. Jurnal Keuangan dan Perbankan. Th. X. No 2. Surabaya.

Kadir, A. (2015). Pengaruh Keadilan Organisasi dan Budaya Organisasi terhadap Kepuasan Gaji, Komitmen Organisasi dan Kinerja. Jurnal Keuangan dan Perbankan. Vol. 7. No. 2. September 2005: 171-188

Dipublikasikan Oleh :

UPT Publikasi dan Pengelolaan Jurnal

Universitas Islam Kalimantan Muhammad Arsyad Al-Banjari Banjarmasin 
M. Yuliansyah, I Nyoman Sujana Degeng, Bambang Budi Wiyono, dan Achmad Supriyanto Jurnal Bimbingan dan Konseling Ar-Rahman

Volume 4, Nomor 2, Tahun 2018

e-ISSN 2477-6300

Kerlinger, P., N. (2015). Beheviora Research. New York: Holt Rinehart \& Winston.

Kosasi, R. (2012). Profesi Keguruan. Jakarta: Rineka Cipta.

Kreitner, R. \& Kinicki. (2015). Perilaku Organisasi. Buku 1. Edisi Kelima. Jakarta: Salemba Empat.

Kreitner, R. andKinicki, A. (2014). Organizational Behavior. Fifth Edition. McGraw. Hill. New York

Litwin \& Stringer. "Definisi Iklim Organisasi", (http://jurnal-sdm.blogspot.com), diakses 29 Agustus 2018.

Locke, E., A. (2014). Esensi Kepemimpinan (terjemahan). Jakarta: Mitra Utama.

Lok \& Crawford. (2014). The Effect of organizational culture and leadership style on job satisfaction and organizational commitment across-National Comparison. The Journal of Management Development.Vol. 23. No. 4. 321-337.

Luthans, F. (2012). Organizational Behavior. New York: Me Graw-Hill.

Luthans, Fred. (2015). Perilaku Organisasi. Diterjemahkan oleh Vivin Andika. Yuwono dkk. Edisi Pertama, Penerbit Andi Offset. 